\title{
Tilt signals at Mount Melbourne, Antarctica: evidence of a shallow volcanic source
}

\author{
Salvatore Gambino, Marco Aloisi, Giuseppe Falzone \& Angelo Ferro \\ Catania Department, National Institute of Geophysics and Volcanology, Piazza Roma 2, IT-95123 Catania, Italy
}

Keywords

Tilt monitoring; volcanic dynamics; physics volcanology; ground deformation; Victoria Land.

\section{Correspondence}

Salvatore Gambino, Catania Department, National Institute of Geophysics and Volcanology, Piazza Roma 2, IT-95123 Catania, Italy. E-mail: salvatore.gambino@ ingv.it

\begin{abstract}
Mount Melbourne $\left(74^{\circ} 21^{\prime} \mathrm{S}, 164^{\circ} 43^{\prime} \mathrm{E}\right)$ is a quiescent volcano located in northern Victoria Land, Antarctica. Tilt signals have been recorded on Mount Melbourne since early 1989 by a permanent shallow borehole tiltmeter network comprising five stations. An overall picture of tilt, air and permafrost temperatures over 15 years of continuous recording data is reported. We focused our observations on long-term tilt trends that at the end of 1997 showed coherent changes at the three highest altitude stations, suggesting the presence of a ground deformation source whose effects are restricted to the summit area of Mount Melbourne. We inverted these data using a finite spherical body source, thereby obtaining a shallow deflation volume source located under the summit area. The ground deformation observed corroborates the hypothesis that the volcanic edifice of Mount Melbourne is active and should be monitored multidisciplinarily.
\end{abstract}

To access the supplementary material for this article, please see the supplementary files under Article Tools, online.
Ground deformation studies of volcanoes are fundamental for forecasting eruptions and better understanding magmatic processes (Dzurisin 2003). Spatial and temporal (short- and long-term) patterns of ground deformation are detected by using different techniques such InSAR, GPS, tiltmeters, strainmeters, EDM and levelling and results are usually related to changes in the volume and location of magma. Especially at volcanoes with steam vents, ground deformation can also originate from movements of geothermal fluids, where the fluid dynamic may be caused by heating of the geothermal reservoir (e.g., Nakaboh et al. 2003; Battaglia et al. 2006).

The frequent occurrence of long-term ground deformation (months-years), in open and closed volcanic systems, has recently been shown using satellite techniques (e.g., Chaussard et al. 2013; Henderson \& Pritchard 2013), levelling (e.g., Murase et al. 2014), EDM (Battaglia et al. 2006) and, more rarely, tilt (Bonaccorso et al. 2015). Shallow borehole tiltmeters are used to monitor the ground deformation of volcanoes throughout the world since they are able to measure precise tilt variations
(Dzurisin 1992, 2003; Ferro et al. 2011). These changes range from slow (months-years) to fast (minutes-days), highlighting different processes occurring at volcanoes (Gambino et al. 2014). In particular, slow variations indicate the inflation/deflation of the edifice caused by volume changes in magma reservoirs (e.g., de Zeeuw-van Dalfsen et al. 2005) or movements of geothermal fluids (e.g., Nakaboh et al. 2003). Tilt measurements have revealed, in different monitored volcanic areas, middle and long-term ground deformation related to edifice inflation/deflation, such as at Piton de la Fournaise (Fontaine et al. 2014), Mount Etna (Bonaccorso et al. 2004), Stromboli (Bonaccorso et al. 2008; Bonaccorso et al. 2009), Vulcano (Gambino et al. 2007) and Vesuvius (Ricco et al. 2013).

Located in northern Victoria Land, Mount Melbourne (2732 $\mathrm{m}$ a.s.l.) is a large stratovolcano (Fig. la) belonging to the McMurdo Volcanic Group (Kyle 1989) and is one of the closed conduit volcanoes in Antarctica with the potential for large-scale explosive eruptions. Physical volcanological studies aimed at studying Mount Melbourne's 


\section{Abbreviations in this article}

EDM: electronic distance measurements

GA: genetic algorithm

GPS: global positioning system

InSAR: interferometric synthetic aperture radar

PS: pattern search

VLNDEF: victoria land network for deformation control

internal dynamics began in 1988 within the framework of the Italian Antarctic Research Programme. A tilt network of five permanent continuously recording stations was installed in 1988-89 (Figs. 1b, 2) and a seismic network in 1990 (Bonaccorso et al. 1996; Bonaccorso, Gambino, Falzone et al. 1997). Gambino \& Privitera (1996) identified and characterized local seismicity at Mount Melbourne. Several seismic analyses, performed on a data set of 17 micro-earthquakes, suggested these events were either "long-period events" (e.g., Chouet 1992), indicating the active presence of fluids in source processes, or were linked to fracturing processes in a medium in transition between the brittle and plastic states (Gambino \& Privitera 1996). On the whole, seismic and tilt data indicate that Mount Melbourne is a quiescent volcano with its own slow, but continual, internal dynamics (Bonaccorso et al. 1995; Bonaccorso, Gambino \& Privitera 1997).

Here we report observations and analyses of 15 years of continuous ground tilt collected at Mount Melbourne that highlight changes and suggest a possible internal volcanic source.

\section{Mount Melbourne volcano}

Mount Melbourne is a volcanic edifice situated between Terra Nova and Wood bays in northern Victoria Land, with a summit caldera of about $1 \mathrm{~km}$ in diameter and characterized by fumarolic activity (Nathan \& Schulte 1967; Keys et al. 1983; Kyle 1989; Wörner \& Viereck 1989). Mount Melbourne is one of the stratovolcanoes in the McMurdo Volcanic Group, which has developed along the western margin of the Ross Sea in Victoria Land, and parallel to the Transantarctic Mountains (Kyle 1989). This area (Fig. la) was recently affected by distensive tectonics on the north-west-south-east structural system forming the Rennick Graben to the north and on the NNE-SSE system to the south, evidenced by the Nansen Graben (Skinner 1983; Carmignani et al. 1989; Lanzafame \& Villari 1991). The volcanic field seems to have formed at the intersection of these systems and the development of the volcanic activity is generally related to the apparent discontinuity of the two structural systems (Lanzafame \& Villari 1991).

Volcanism in the Mount Melbourne area started during the upper Pliocene with the formation of the Cape Washington shield volcano. During the lower and middle Pleistocene, volcanism migrated towards the Transantarctic Mountains, while in the upper Pleistocene/Holocene the Mount Melbourne stratovolcano was associated with the establishment of a crustal magma chamber (Giordano et al. 2012). The volcanic activity at Mount Melbourne is testified by blankets of pyroclastic pumice and scoria fall (a)

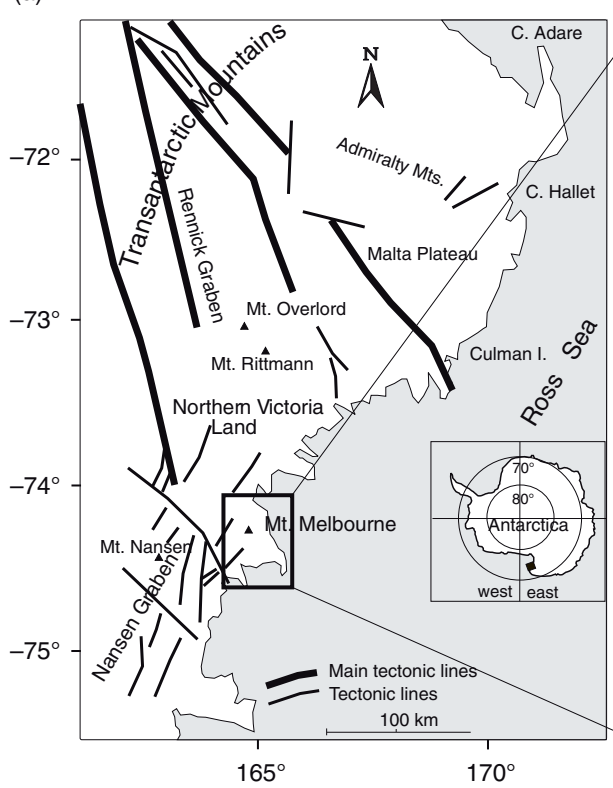

(b)

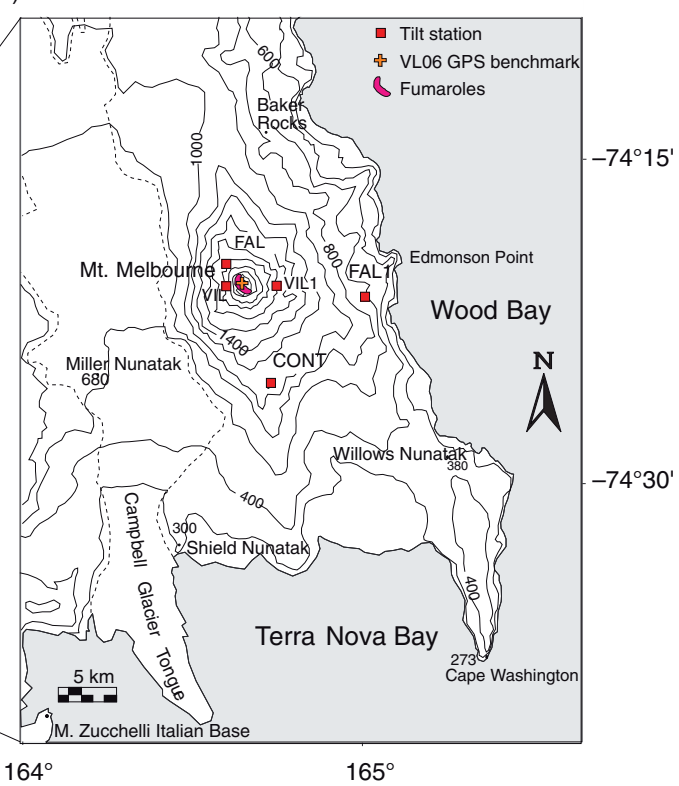

Fig. 1 Tectonic sketch map of (a) northern Victoria Land (redrawn from Carmignani et al. 1989). (b) Map of the permanent tilt network on Mount Melbourne. 


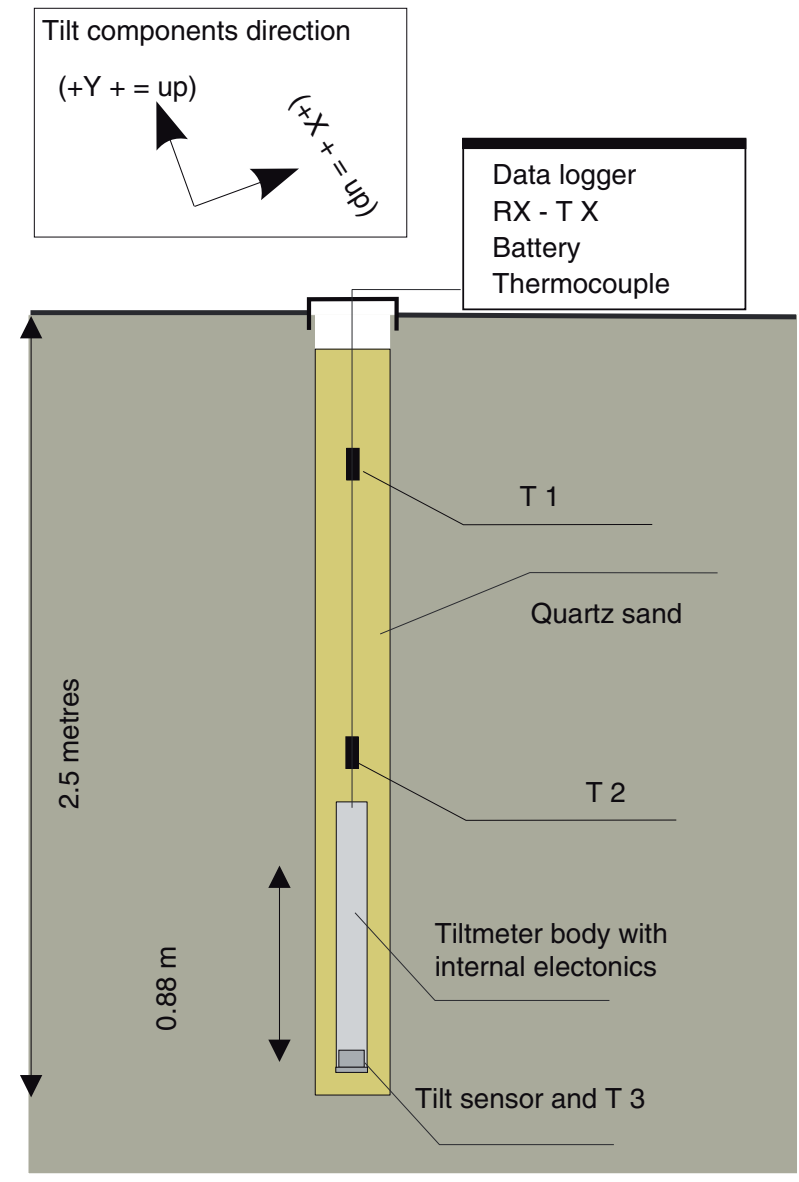

Fig. 2 Scheme of a borehole tiltmeter.

around the eastern and southern flanks (Wörner $\delta$ Viereck 1989), by pyroclastic layers interbedded with the summit snows (Nathan \& Schulte 1967; Keys et al. 1983) and by the moderate fumarolic activity $\left(59^{\circ} \mathrm{C}\right.$ at $25 \mathrm{~cm}$ depth) in the summit area (Lyon \& Giggenbach, 1974; Keys et al. 1983; Cremisini et al. 1991). The most recent activity is believed to date back no further than 200 years (Adamson \& Cavaney 1967; Nathan \& Schulte 1967; Keys et al. 1983). On the basis of the depth at which tephra layers from the most recent explosive activity at Mount Melbourne were found within the ice cap, Lyon (1986) proposed that the most recent eruption probably occurred between 1862 and 1922 .

\section{The tilt network}

In early 1989, five continuous recording sensors (Figs. 1b, 2; Supplementary Fig. S1) consisting of biaxial borehole bubble sensors were installed at a depth of about $2.5 \mathrm{~m}$ (Bonaccorso et al. 1995). The tilt sensors have a 0.1 microradian resolution (Applied Geomechanics Model 722) and two components trend radially (Tilt $X$ ) and tangentially (Tilt Y) with respect to the Mount Melbourne summit. In particular, increases in the radial component indicate inflation of the crater area, while positive variations of the tangential component indicate inflation at $90^{\circ}$ counter-clockwise with respect the radial component. The boreholes also have two thermocouples (T1, T2) (copperconstantan type, $0.1{ }^{\circ} \mathrm{C}$ precision) shaft (mean depths 1.0 and $1.9 \mathrm{~m}$, respectively) and a tilt temperature sensor at the ends of the instrument that records the permafrost temperature. The control data-logger was programmed for 48 data/day sampling (one sample every $30 \mathrm{~min}$ ) and includes acquisition of the two tilt components, air (Tbox) and ground temperatures and instrumental control parameters, such as battery and DC/DC voltage. Each station is equipped with solid state memories which guarantee data acquisition through the winter months, while high capacity batteries power the station.

\section{Data}

The tilt network data set spans the beginning of 1989 to the end of 2003. Partial interruptions were caused by data-logger auto-protection, which activates under a voltage threshold of about $10 \mathrm{~V}$, or by electronic malfunctioning, which is to be expected under $-35^{\circ} \mathrm{C}$. Some interruptions took place when the external temperature oscillations began to wane and there was no longer sunlight. Data acquisition ended in 2003 with reduction in personnel stationed in Antarctica.

\section{Air and ground temperatures}

The permanent tilt network has allowed the continuous recording of air and permafrost temperature. Some features of temperature data are shown in Fig. 3, which presents one month of signals at different depths; summer daily fluctuations were attenuated with depth ranging from over $10-15^{\circ} \mathrm{C}$ at the surface (Tbox), to about $2-4^{\circ} \mathrm{C}$ at $-0.5 \mathrm{~m}(\mathrm{~T} 1)$, to $1-2^{\circ} \mathrm{C}$ at $-1.5 \mathrm{~m} \mathrm{(T2)}$ and down to

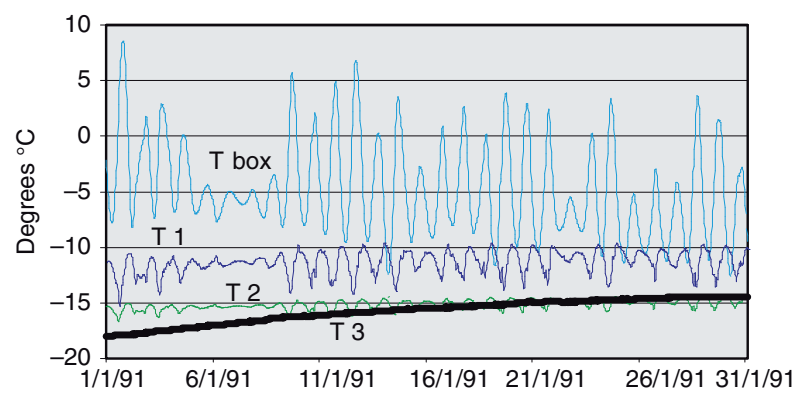

Fig. 3 Example of daily cycle recorded at the four temperature sensors of the CONT station in January 1991 (redrawn from Gambino 2005). 
approximately zero at the deeper sensor (T3 at $-2.5 \mathrm{~m})$. Seasonal temperature changes at Mount Melbourne are marked. Air temperature changes exceeded $30^{\circ} \mathrm{C}$ at all the stations while ground temperature changes decrease with depth (Fig. 4; Bonaccorso et al. 1995).

T3 at the highest station (VIL, $2030 \mathrm{~m}$ a.s.l.) showed mean daily permafrost temperature between -18 and $-33^{\circ} \mathrm{C}$, while for the lower altitude station (FALl, $800 \mathrm{~m}$ a.s.l.) the range was between -9 and $-22^{\circ} \mathrm{C}$. An analysis of T3 permafrost temperatures recorded at VIL, CONT, FALl and VILl stations between 1989 and 1998, performed by Gambino (2005), highlighted a negative trend for all stations and indicate a cooling of this area in accordance with climatic studies of northern Victoria Land (e.g., Kwok \& Comiso 2002).

\section{Tilt signals}

Shallow borehole tilt data are generally affected by diurnal and seasonal noise linked to temperature effects (e.g., Bonaccorso et al. 1999). At Mount Melbourne, diurnal fluctuations were observed only during the Antarctic summer and were in the range of 2-12 microradians (Bonaccorso et al. 1995); for long-term analysis we applied a moving average of 96 samples (two days) in order to remove the daily high frequency noise. The obtained tilt signals are shown in Figs. 5 and 6; signals show seasonal fluctuations that range between 10 and 20 microradians. Although the signals are affected by annual variations due to the seasonal temperature changes, the long-term is easily identified and a filtering of these effects is not necessary.

Long-term trends recorded in tilt data comprise real ground deformation, the local site dynamic and instrumental drift (e.g., Kohl \& Levine 1993; Anderson et al. 2010). The secular marked trends visible at VIL and to a lesser degree at CONT (Figs. 5, 6, phase 2) stations may be linked to instrumental drifts.

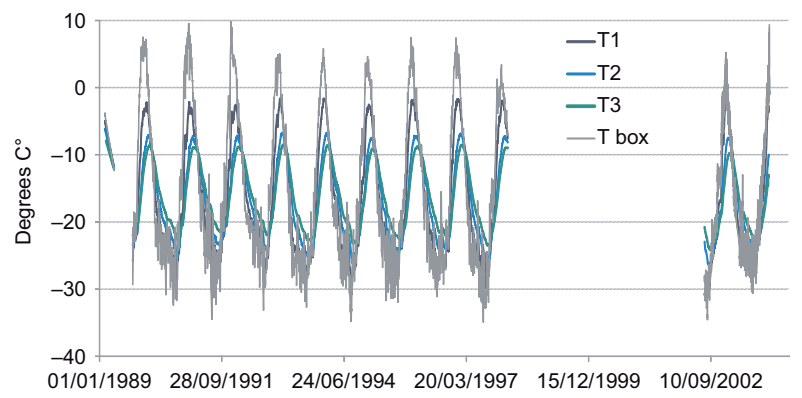

Fig. 4 Air and permafrost temperatures historical series recorded at the FAL1 station. Data have been filtered by applying a moving average of 96 samples, to remove the summer daily frequency, and successively resampled for each day.

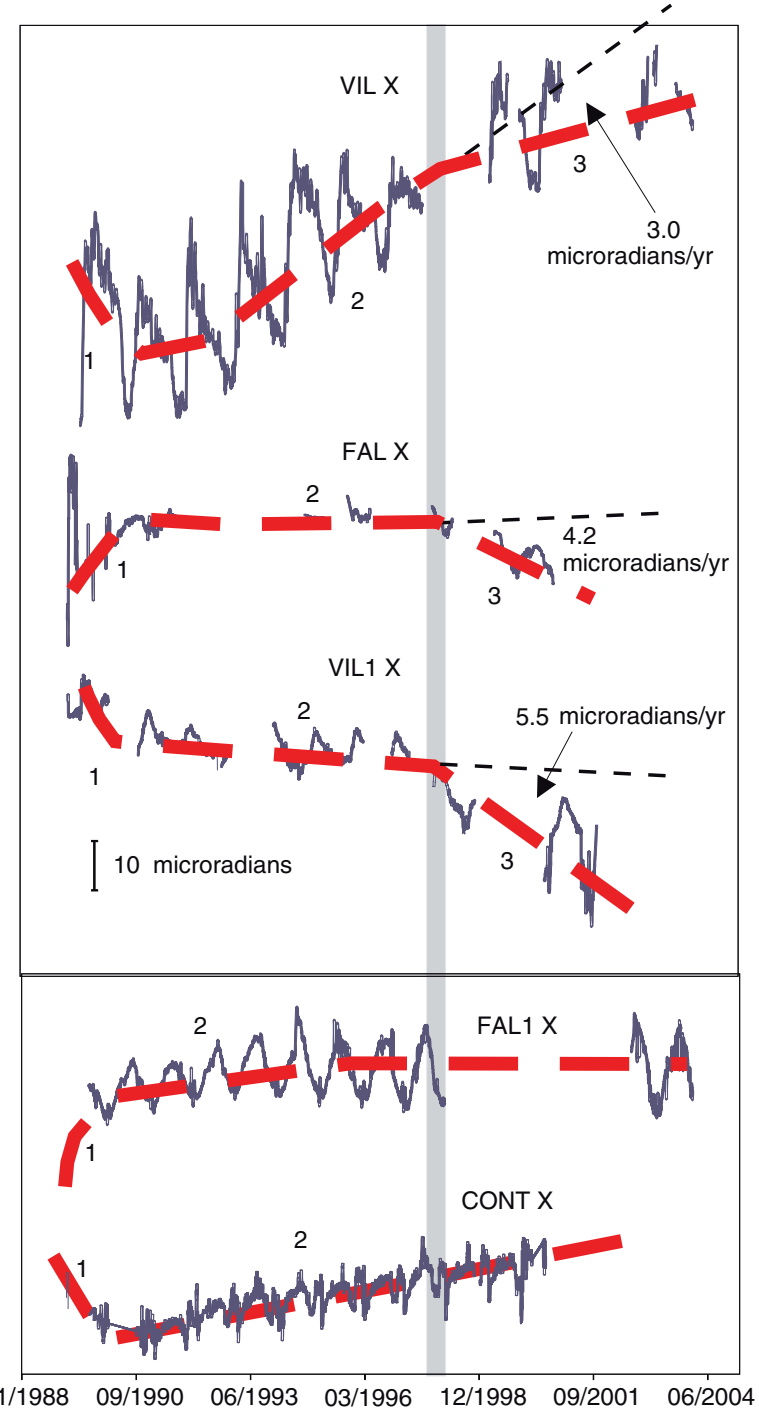

Fig. 5 Radial tilt component at the five stations. Data filtered to remove the high frequency noise by applying a moving average of 96 samples (two days). Numbers define the three phases discussed in detail in the text.

A general picture of Mount Melbourne tilt signals (Figs. 5, 6) evidenced two or three phases for almost each signal. In particular, a first phase (1), lasting about one year, was present on almost all signals and was dominated by instrument/site stabilization effects after installation (AGI 1993). Successively, from 1990 to the end of 1997, tilt trends (phase 2) were constant, while at the end of 1997 and the beginning of 1998 the radial components of the three summit stations (VIL, FAL, VIL1) showed a lowering of their trends almost contemporaneously (phase 3). We have estimated these changes, in comparison to the stable 1990-97 period, at -3.0 , -4.2 and -5.5 microradians/year, respectively, for VIL, FAL and VILl stations (Fig. 5). 


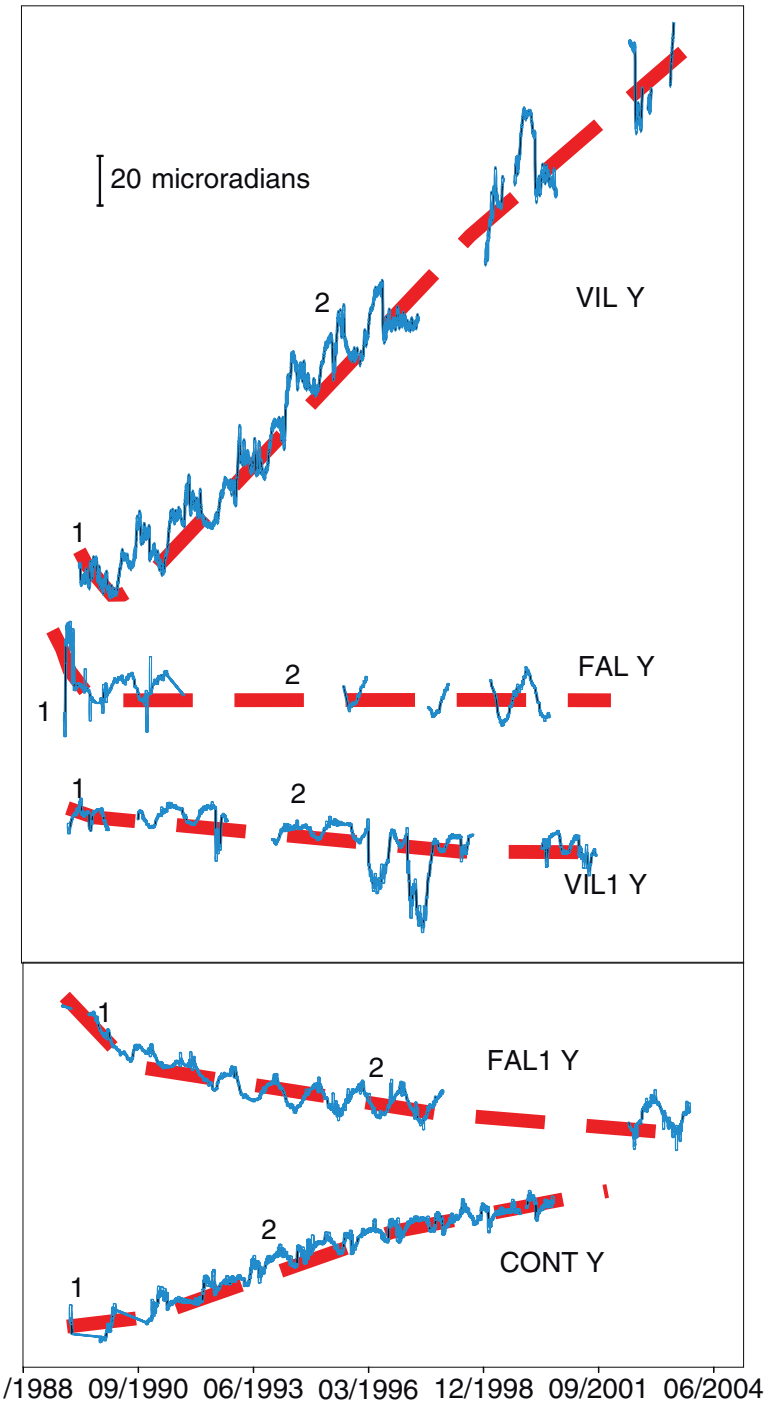

Fig. 6 Tangential tilt component at the five stations. Data filtered to remove the high frequency noise by applying a moving average of 96 samples (two days). Numbers define the three phases discussed in detail in the text.

\section{Global positioning system}

GPS measurements at the Mount Melbourne area have been performed since 1990-91, when a geodetic GPS network was established to monitor the deformation of the volcano (Capra et al. 1998). The network, made up of 12 benchmarks, has been surveyed four times: 1990-91, 1993-94, 1995 and 1997-98 by GPS methodology in static modality. The results obtained with different software and different approaches gave significantly different results (Capra et al. 1998). The development of modern space geodesy techniques and requests made by the scientific community to extend the area investigated by GPS observations led to deploying a new network of 32 benchmarks (VLNDEF) covering the entire northern Victoria Land area (Dubbini et al. 2010) designed for geodynamic purposes. This network includes the VL06 benchmark (Fig. Ib) positioned on the summit area of Mount Melbourne; during 1999-2003 VL06 showed no significant movements (Capra et al. 2007). In the successive period (until 2006), VL06 showed an uplift of 6.14 $( \pm 1.62) \mathrm{mm} /$ year without horizontal changes (Dubbini et al. 2010). The VLNDEF processed GPS data are the results of the primary role of the tectonics acting on northern Victoria Land (Dubbini et al. 2010).

\section{Modelling}

We inverted the tilt data in order to image the observed deformation pattern under the conditions of a homogeneous, isotropic and elastic half-space. We considered the estimated changes at VIL, VILl and FAL, assigning no changes to FAL and CONT stations.

A pressure source was modelled using the finite spherical body solution of McTigue (1987), obtaining a plausible data fit (Fig. 7). We chose this source model since, in this case, it has a good trade-off between the number of degrees of freedom and the obtained data fit. It is worth noting that we have few available recorded data (five tiltmeters and one GPS station) and it is not possible to use a more complex pressure source. The McTigue pressure source is determined by five parameters: the coordinates " $\mathrm{x}_{\mathrm{C}}$ " " $\mathrm{y}_{\mathrm{c}}$," and " $\mathrm{z}_{\mathrm{C}}$ " of the sphere centre, the radius "a" and the pressure " $\mathrm{P}$ " on the surface of the model. The volume variation $\Delta \mathrm{V}$ was calculated as $\Delta \mathrm{V}=\mathrm{Pa}^{3} \pi / \mu$, according to Tiampo et al. (2000), using a suitable rigidity modulus $\mu$ for volcanic region of 5 GPa (e.g., Bonafede et al. 1986; Davis 1986; Newman et al. 2006). The effects of the topography were included using the varying-depth model of Williams \& Wadge (1998), which assumes a different elevation for each recording station corresponding to the actual elevation of the benchmark. As said before, the medium was assumed homogeneous and isotropic with a Young modulus of $75 \mathrm{GPa}$ and a Poisson ratio of 0.25 chosen as typical values for volcanic region.

To estimate the model parameters, we performed an analytical inversion using an optimization approach based on the use of GAs (Goldberg 1989). GAs implement strategies based on the simulation of natural laws, in the evolutionistic sense. Using probabilistic transition rules during iterations, GAs search for the best value of the "fitness" function to be optimized starting from a "population" of points belonging to the function domain and not from a single one. In this way, the probability of finding local minima is reduced. Subsequently, to better refine the previously solution, we applied the PS technique 


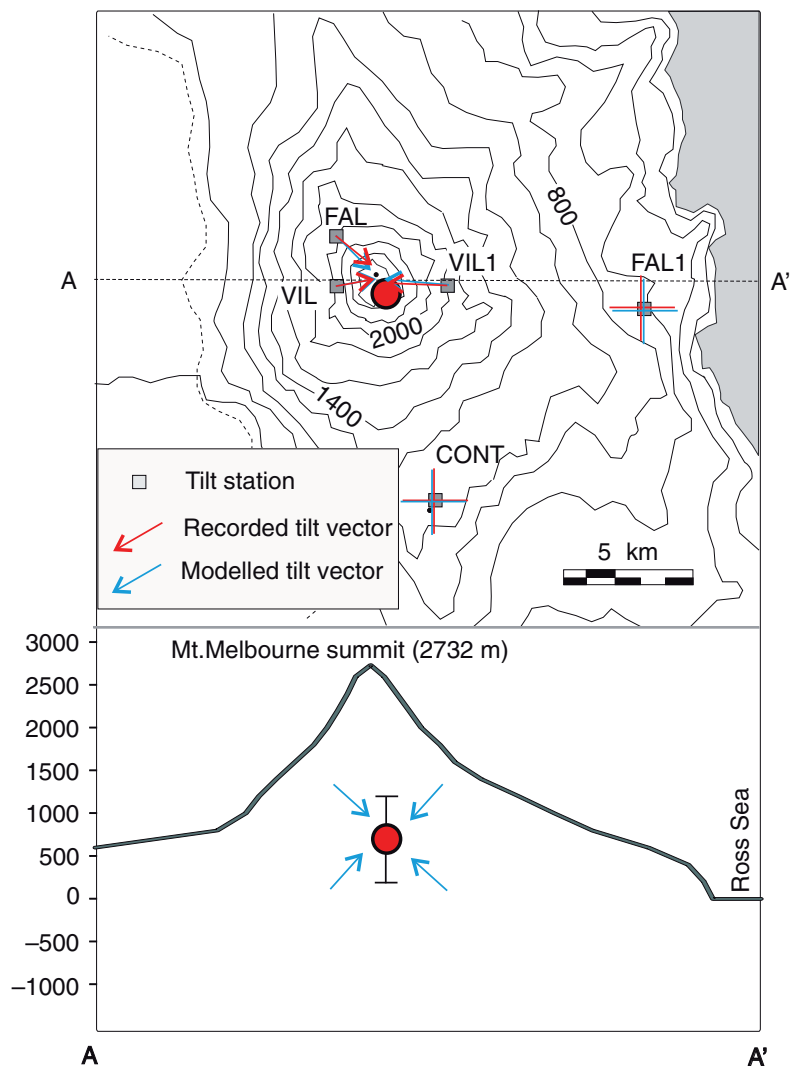

Fig. 7 Location and east-west cross-section of the pressure source modelled. The vertical error is reported on the cross section.

(Lewis \& Torczon 1999; Lewis et al. 2000) and the nonlinear least squares method (Kelley 1999). PS methods are a class of direct search methods for solving nonlinear optimization problems. These methods are characterized by a series of exploratory moves that consider the behaviour of the objective function at a pattern of points, all of which lie on a rational lattice. The exploratory moves consist of a systematic strategy for visiting the points in the lattice in the immediate vicinity of the current iterate. Moreover, the nonlinear least squares method, applied in this study to the solution found by the PS method, is the form of least squares analysis used to fit a set of $m$ observations with a model that is non-linear in $n$ unknown parameters. The method approximates the model by a linear one and refines the $n$ parameters by successive iterations.

To estimate the uncertainty of each optimized model parameter, a jackknife resampling method (Efron 1982) was adopted.

This technique requires several optimizations. First, we estimate the solution by using all available data, $D_{n}$, composed of $n$ data. Then, by removing one input measure- ment at a time, we estimate a new solution using the data $D_{n-1, i}$, where the subscript indicates the size of the data set and the index of the removed measurement. Then, the new solution estimator is derived as:

$$
D_{n}^{*}=n D_{n}-(n-1) \bar{D}_{n-1}
$$

where

$$
\bar{D}_{n-1}=\frac{\sum_{i=1}^{n} D_{n-1, i}}{n}
$$

Variance is estimated using the following formula.

$$
\sigma_{\mathfrak{f}}^{2}=\frac{n-1}{n} \sum_{i=1}^{n-1}\left(D_{n-1, i}-\bar{D}_{n-1}\right)^{2}
$$

Some quantitative examples of application of these methods can be found in work by Fernàndez et al. (2001), Tiampo et al. (2004), Aloisi et al. (2009) and Patanè et al. (2013). The final optimal solution is shown in Fig. 7 and Table 1. In Table 1, we report the misfit between the observed and modelled data as the value of the weighted root mean square error:

$$
W R M S E=\sqrt{\sum_{i=U_{p}} \frac{\left(D_{i}-D C_{i}\right)^{2}}{\varepsilon_{i}}},
$$

where $\mathrm{D}_{\mathrm{i}}$ is the measured variation with an error $\varepsilon_{i}$ at the $i$-th benchmark (0.5 microradians for tilt observations $0.005 \mathrm{~m}$ for horizontal displacements, $0.02 \mathrm{~m}$ for vertical displacements) and $D C_{i}$ is the respective modelled value. The used errors $\varepsilon_{i}$ are typical measurement uncertainties.

We obtained a deflating source at a depth of about $+0.8 \mathrm{~km}$ (a.s.l.) with an uncertainty of about $\pm 0.6 \mathrm{~km}$. Regarding the modelled variation in volume (Table 1), we estimated a value of about $-2.1( \pm 1.7) 10^{6} \mathrm{~m}^{3}$.

\section{Discussion and conclusions}

Long-term trends recorded on tiltmeters are a combination of real ground tilt (tectonic, volcanic), local and installation instability and instrumental drift. During the 1990-97 period, tilt data on Mount Melbourne indicate a stable period in which tilt trends do not change. This state changed in the 1998-2002 interval when radial components of the three summit stations show a lowering of their trends. The fact that long period trends altered at about the same time on different instruments after 
Table 1 Best fitting range for the model.

\begin{tabular}{lcc}
\hline Parameters & Source & Error \\
\hline $\mathrm{x}_{\mathrm{c}}(\mathrm{m})$ & 490989 & 294 \\
$\mathrm{y}_{\mathrm{c}}(\mathrm{m})$ & 1748858 & 129 \\
$\mathrm{z}_{\mathrm{c}}(\mathrm{m})$ & 768 & 614 \\
$\mathrm{a}(\mathrm{m})$ & 129 & 18 \\
$\mathrm{P}(\mathrm{Pa})$ & $-1.6 \mathrm{E}+09$ & $6.0 \mathrm{E}+08$ \\
$\Delta \mathrm{V}\left(\mathrm{m}^{3}\right)$ & $-2.1 \mathrm{E}+06$ & $1.7 \mathrm{E}+06$ \\
\hline
\end{tabular}

7-8 years of stability suggests that a new ground deformation source was active after the end of 1997.

These changes are a coherent indication of a general deflation and contraction of the Mount Melbourne edifice during 1998-2002.

We sought to obtain a model for these deformations and an optimal solution (Fig. 7, Table 1) shows a deflation source ca. 1.0-2.2 km deep with respect to Mount Melbourne's summit caldera (2400 m a.s.l.). Modelling employed tilt data but we also considered the possibility of introducing discrete GPS measurements at VL06; even if VL06 did not show significant variations during 19992003 , it was successively affected by a tectonic uplift of $6.1 \mathrm{~mm} /$ year (Dubbini et al. 2010). Assuming the regional tectonic uplift as a constant, we hypothesized that between 1998 and 2002 a lowering of about $6 \mathrm{~mm} /$ year at Mount Melbourne's summit counteracted the tectonic effects (no uplift during the 1999-2003 period). If we include data from the VL06 station during the inversion procedure, we obtain a pressure source characterized by a similar location below the summit area, compatible with model parameter uncertainties estimated using tilt data alone.

It is difficult to imagine that magma may have had a role in producing this ground deformation: Mount Melbourne is a quiescent volcano characterized by fumarolic emanations in the caldera area and a shallow deflation source suggests a geothermal rather than a magmatic type source. Long periods of deflation and contraction have been linked to shallow geothermal fluids dynamics at different volcanoes: at Kuju (Japan), a spherical source $600 \mathrm{~m}$ deep (from surface) was proposed by Nakaboh et al. (2003) to explain six years of EDM data; at Vulcano (Italy), an ellipsoidal source at ca. $400 \mathrm{~m}$ depth explained the 1990-96 EDM and levelling data (Gambino \& Guglielmino 2008); 2006-2013 precise levelling surveys at Tatun volcano (Taipei) showed deformation in relation to the hydrothermal deflation source at a depth of $2 \mathrm{~km}$ (Murase et al. 2014).

The results obtained at Mount Melbourne seem to be comparable with other volcanoes and point to a volume decrease linked to water/fluid removal from the upper levels of the edifice by heating of a shallow geothermal reservoir; the presence of active fluids at Mount Melbourne was also suggested by seismicity (Gambino \& Privitera 1996).

The data and model presented here indicate that Mount Melbourne is dynamic and active and bears watching for future changes in activity that may result in eruption, especially since it has been demonstrated (Lyon 1986; Kyle 1989) that the last eruption occurred sometime between 1862 and 1922 . While eruptive activity is not likely to pose any hazard given the lack of population, infrastructure and air traffic, examination of the volcano may provide further insights into the tectonics of the region and a window into how the volcanoes of the McMurdo group work as a contrast to the better studied, but probably more unique, Mount Erebus.

\section{Acknowledgements}

We are particularly indebted to Prof. Letterio Villari, who conceived the Mt. Melbourne tilt network and struggled hard to achieve it. We thank Mike Poland and an anonymous reviewer for their critical reading of the manuscript and constructive comments. We also thank F. Cannavò for the modelling programme codes and S. Conway for improving the English of this paper.

\section{References}

Adamson R.G. \& Cavaney R.J. 1967. Volcanic debris layers near Mount Melbourne, northern Victoria Land, Antarctica. New Zealand Journal of Geology and Geophysics 10, 409-421.

AGI (Applied Geomechanics Incorporation) 1993. Notes on temperature coefficients and long-term drift of Applied Geomechanics tiltmeters. Report no. A-93-1001. Santa Cruz, CA: Applied Geomechanics Incorporation.

Aloisi M., Bonaccorso A., Cannavò F., Gambino S., Mattia M., Puglisi G. \& Boschi E. 2009. A new dike intrusion style for the Mount Etna May 2008 eruption modelled through continuous tilt and GPS data. Terra Nova 21, 316-321.

Anderson K., Lisowski M. \& Segall P. 2010. Cyclic ground tilt associated with the 2004-2008 eruption of Mount St. Helens. Journal of Geophysical Research - Solid Earth 115, B11201, doi: http://dx.doi.org/10.1029/2009JB007102

Battaglia M., Troise C., Obrizzo F., Pingue F. \& De Natale G. 2006. Evidence for fluid migration as source of deformation at Campi Flegrei caldera (Italy). Geophysical Research Letters 33, L01307, doi: http://dx.doi.org/10.1029/2005GL024904

Bonaccorso A., Bonforte A. \& Gambino S. 2015. Twenty-five years of continuous borehole tilt and vertical displacement data at Mount Etna: insights on long-term volcanic dynamics. Geophysical Research Letters 42, 10222-10229.

Bonaccorso A., Bonforte A., Gambino S., Mattia M., Guglielmino F., Puglisi G. \& Boschi E. 2009. Insight on recent Stromboli eruption inferred from terrestrial and satellite ground 
deformation measurements. Journal of Volcanology and Geothermal Research 182, 172-181.

Bonaccorso A., Campisi O., Falzone G. \& Gambino S. 2004. Continuous tilt monitoring: lesson from 20 years experiences at Mt. Etna. In A. Bonaccorso et al. (eds.): Mt. Etna: volcano laboratory. Pp. 307-320. Washington, DC: American Geophysical Union.

Bonaccorso A., Falzone G. \& Gambino S. 1999. An investigation into shallow borehole tiltmeters. Geophysical Research Letters 26, 1637-1640.

Bonaccorso A., Falzone G., Gambino S. \& Villari L. 1995. Tilt signals recorded at Mt Melbourne Volcano (northern Victoria Land, Antarctica) between 1989-94. Terra Antartica 2, $111-116$

Bonaccorso A., Gambino S., Falzone G. \& Privitera E. 1996. Physics volcanological studies in the activity framework of the Mt. Melbourne Observatory (northern Victoria Land, Antarctica). In A. Meloni \& A. Morelli (eds.): Italian geophysical observatories in Antarctica. Pp. 67-92. Bologna: Compositori.

Bonaccorso A., Gambino S., Falzone G. \& Privitera E. 1997. The volcanological observatory of Mount Melbourne, northern Victoria Land, Antarctica. In C.A. Ricci (ed.): The Antarctic region: geological evolution and processes. Pp. 1083-1086. Siena: Terra Antartica Publication.

Bonaccorso A., Gambino S., Guglielmino F., Mattia M., Puglisi G. \& Boschi E. 2008. Stromboli 2007 eruption: deflation modeling to infer shallow-intermediate plumbing system. Geophysical Research Letters 35, L0631 1, doi: http://dx.doi.org/ 10.1029/2007GL032921

Bonaccorso A., Gambino S. \& Privitera E. 1997. A geophysical approach to the dynamics of Mt. Melbourne (northern Victoria Land, Antarctica). In C.A. Ricci (ed.): The Antarctic region: geological evolution and processes. Pp. 531-538. Siena: Terra Antartica Publication.

Bonafede M., Dragoni M. \& Quareni F. 1986. Displacement and stress fields produced by a centre of dilation and by a pressure source in a viscoelastic half-space: application to the study of ground deformation and seismic activity at Campi Flegrei, Italy. Geophysical Journal of the Royal Astronomical Society 87, 455-485.

Capra A., Mancini F. \& Negusini M. 2007. GPS, a geodetic tool for geodynamics in northern Victoria Land, Antarctica. Antarctic Science 19, 107-114.

Capra A., Radicioni F. \& Vittuari L. 1998. Italian geodetic network as reference frame for geodynamic purposes (Terra Nova Bay-Victoria Land-Antarctica). In R. Forsberg et al. (eds.): Geodesy on the move. Pp. 498-503. Berlin: Springer.

Carmignani L., Ghezzo G., Gosso G., Lombardo B., Meccheri M., Montrasio A., Pertusati P.C. \& Salvini F. 1989. Geology of the Wilson Terrane in the area between David and Mariner glaciers, Victoria Land (Antarctica). Memorie della Società Geologica Italiana 33, 77-97.

Chaussard E., Amelung F. \& Aoki Y. 2013. Characterization of open and closed volcanic systems in Indonesia and Mexico using InSAR time series. Journal of Geophysical ResearchSolid Earth 118, 3957-3969.
Chouet B.A. 1992. A seismic model for the source of long period events and harmonic tremor. In P. Gasparini et al. (eds.): Volcanic seismology. Pp. 133-156. Berlin: Springer.

Cremisini C., Gianelli G., Mussi M. \& Torcini S. 1991. Geochemistry and isotope chemistry of surface waters and geothermal manifestations at Terra Nova Bay (Victoria Land, Antarctica). Memorie della Società Geologica Italiana 46, 463-475.

Davis P.M. 1986. Surface deformation due to inflation of an arbitrarily oriented triaxial ellipsoidal cavity in an elastic half-space, with reference to Kilauea volcano, Hawaii. Journal of Geophysical Research - Solid Earth and Planets 91, 7429-7438.

de Zeeuw-van Dalfsen E., Rymer H., Sigmundsson F. \& Sturkell E. 2005. Net gravity decrease at Askja volcano, Iceland: constraints on processes responsible for continuous caldera deflation, 1988-2003. Journal of Volcanology and Geothermal Research 139, 227-239.

Dubbini M., Cianfarra P., Casula G., Capra A. \& Salvini F. 2010. Active tectonics in northern Victoria Land (Antarctica) inferred from the integration of GPS data and geologic setting. Journal of Geophysical Research - Solid Earth 115, B12421, doi: http://dx.doi.org/10.1029/2009JB007123

Dzurisin D. 1992. Electronic tiltmeters for volcano monitoring: lessons from Mount St. Helens. U.S. Geological Survey Bulletin 1966, 69-83.

Dzurisin D. 2003. A comprehensive approach to monitoring volcano deformation as a window on the eruption cycle. Reviews of Geophysics 41, article no. 1001, doi: http://dx.doi. org/10.1029/2001RG000107

Efron B. 1982. The jackknife, bootstrap and other resampling plans. Philadelphia: Society for Industrial and Applied Mathematics.

Fernàndez J., Tiampo K.F., Jentzsch G., Charco M. \& Rundle J.B. 2001. Inflation or deflation? New results for Mayon volcano applying elastic-gravitational modelling. Geophysical Research Letters 28, 2349-2352.

Ferro A., Gambino S., Panepinto S., Falzone G., Laudani G. \& Ducarme B. 2011. High precision tilt observation at Mt. Etna Volcano, Italy. Acta Geophysica 59, 618-632.

Fontaine F.R., Roult G., Michon L., Barruol G. \& Muro A.D. 2014. The 2007 eruptions and caldera collapse of the Piton de la Fournaise volcano (La Réunion Island) from tilt analysis at a single very broadband seismic station. Geophysical Research Letters 41, 2803-2811.

Gambino S. 2005. Air and permafrost temperature at Mt. Melbourne (1989-1998). Antarctic Science 17, 151-152.

Gambino S., Campisi O., Falzone G., Ferro A., Guglielmino F., Laudani G. \& Saraceno B. 2007. Tilt measurements at Vulcano Island. Annals of Geophysics 50, 233-247.

Gambino S., Falzone G., Ferro A. \& Laudani G. 2014. Volcanic processes detected by tiltmeters: a review of experience on Sicilian volcanoes. Journal Volcanology Geothermal Research $271,43-54$.

Gambino S. \& Guglielmino F. 2008. Ground deformation induced by geothermal processes: a model for La Fossa Crater (Vulcano Island, Italy). Journal of Geophysical 
Research—Solid Earth 113, B07402, doi: http://dx.doi.org/10. 1029/2007JB005016

Gambino S. \& Privitera E. 1996. Mt Melbourne volcano, Antarctica: evidence of seismicity related to volcanic activity. Pure and Applied Geophysics 146, 305-318.

Giordano G., Lucci F., Phillips D., Cozzupoli D. \& Runci V. 2012. Stratigraphy, geochronology and evolution of the Mt. Melbourne volcanic field (north Victoria Land, Antarctica). Bulletin of Volcanology 74, 1985-2005.

Goldberg D.E. 1989. Genetic algorithms in search, optimization and machine learning. Boston, MA: Kluwer.

Henderson S.T. \& Pritchard M.E. 2013. Decadal volcanic deformation in the Central Andes Volcanic Zone revealed by InSAR time series. Geochemistry Geophysics Geosystems 14, $1358-1374$

Kelley C.T. 1999. Iterative methods for optimization. Philadelphia: Society for Industrial and Applied Mathematics.

Keys J., McIntosh W.C. \& Kyle P.R. 1983. Volcanic activity of Mount Melbourne, northern Victoria Land. Antarctic Journal of the United States 18(5), 10-11.

Kohl M.L. \& Levine J. 1993. Measuring low frequency tilts. Journal of Research of the National Institute of Standards and Technology 98, 191-202.

Kwok R. \& Comiso J.C. 2002. Spatial patterns of variability in Antarctic surface temperature: connections to the Southern Hemisphere Annular Mode and the Southern Oscillation. Geophysical Research Letters 29, article no. 1705, doi: http:// dx.doi.org/10.1029/2002GL015415

Kyle P.R. 1989. McMurdo Volcanic Group, western Ross Embayment. In W.E. LeMasurier \& J.W. Thomson (eds.): Volcanoes of the Antarctic Plate and southern oceans. Pp. 19-145. Washington, DC: American Geophysical Union.

Lanzafame G. \& Villari L. 1991. Structural evolution and volcanism in northern Victoria Land (Antarctica): data from Mt. Melbourne-Mt. Overlord-Malta Plateau region. Memorie della Società Geologica Italiana 46, 371-381.

Lewis R.M. \& Torczon V. 1999. Pattern search algorithms for bound constrained minimization. SIAM Journal on Optimization 9, 1082-1099.

Lewis R.M., Torczon V. \& Trosset M.W. 2000. Direct search methods: then and now. Journal of Computational and Applied Mathematics 124, 191-207.

Lyon G.L. 1986. Stable isotope stratigraphy of ice cores and the age of the last eruption at Mount Melbourne, Antarctica. New Zealand Journal of Geology and Geophysics 29, 135-138.

Lyon G.L. \& Giggenbach W.F. 1974. Geothermal activity in Victoria Land, Antarctica. New Zealand Journal of Geology and Geophysics 17, 511-521.

McTigue D.F. 1987. Elastic stress and deformation near a finite sphericalmagma body: resolution of the point source paradox. Journal of Geophysics Research-Solid Earth 92, 12931-12940.

Murase M., Lin C.H., Kimata F., Mori H. \& Pu H.C. 2014. Volcano-hydrothermal activity detected by precise levelling surveys at the Tatun volcano group in northern Taiwan during 2006-2013. Journal of Volcanology and Geothermal Research 286, 30-40.

Nakaboh M., Ono H., Sako M., Sudo Y., Hashimoto T. \& Hurst A.W. 2003. Continuing deflation by fumaroles at Kuju Volcano, Japan. Geophysical Research Letters 30, article no. 1396, doi: http://dx.doi.org/10.1029/2002GL016047

Nathan S. \& Schulte F.J. 1967. Recent thermal and volcanic activity on Mount Melbourne, northern Victoria Land, Antarctica. New Zealand Journal of Geology and Geophysics $10,422-430$.

Newman A.V., Dixon T.H. \& Gourmelen N. 2006. A fourdimensional viscoelastic deformation model for Long Valley Caldera, California, between 1995-2000. Journal of Volcanology and Geothermal Research 150, 244-269.

Patanè D., Aiuppa A., Aloisi M., Behncke B., Cannata A., Coltelli M., Di Grazia G., Gambino S., Gurrieri S., Mattia M. \& Salerno G. 2013. Insights into magma and fluid transfer at Mount Etna by a multi-parametric approach: a model of the events leading to the 2011 eruptive cycle. Journal of Geophysical Research-Solid Earth 118, 3519-3539.

Ricco C., Aquino I., Borgstrom S. \& Del Gaudio C. 2013. 19 years of tilt data on Mt. Vesuvius: state of the art and future perspectives. Annals of Geophysics 56, article no. S0453, doi: http://dx.doi.org/10.4401/ag-6459

Skinner D.N.B. 1983. The geology of Terra Nova Bay. In R.L. Oliver et al. (eds.): Antarctic Earth science. Pp. 150-155. Canberra: Australian Academy of Science.

Tiampo K.F., Fernandez J., Gentzsch G., Charco M. \& Rundle J.B. 2004. Inverting for the parameters of a volcanic source using a genetic algorithm and a model for magmatic intrusion in elastic-gravitational layered Earth models. Computer and Geosciences 30, 985-1001.

Tiampo K.F., Rundle J.B., Fernandez J. \& Langbein J.O. 2000. Spherical and ellipsoidal volcanic sources at Long Valley Caldera, California, using a genetic algorithm inversion technique. Journal of Volcanology and Geothermal Research 102, 189-206.

Williams C.A. \& Wadge G. 1998. The effects of topography on magma chamber deformation models: application to Mt. Etna and radar interferometry. Geophysical Research Letters 25, $1549-1552$.

Wörner G. \& Viereck L. 1989. McMurdo Volcanic Group, western Ross Embayment (Mt. Melbourne). In W.E. LeMasurier \& J.W. Thomson (eds.): Volcanoes of the Antarctic Plate and southern oceans. Pp. 72-78. Washington, DC: American Geophysical Union. 